\title{
SERENISSIME PRINCEPS
}

\section{INDULGENTISSIME DOMINE.}

Piae sunt caussae, nec quidquam cum vanitate habent commune, quibus commotus hanc Plinianorum operum editionem CELSITUdiNi TUAE consecrare ausus sum. Cui enim potius; quam тIBI, studia mea approbari cupiam, DOMINO nostro benignissimo, singulari omnium bonarum artium 
fautori, scholarumque Fuldensium et conditori et instauratori liberalissimo? Tenuis quidem opera est, quam ex instituti ratione huic libro impendere mihi licuit; Plinium tamen, egregium egregii Traiani laudatorem, continet: neque nitor ille, quo redemtor opera eius excoluit, legentiumque oculis commendavit, adspectu Tu 0 erit indignus. In me quidem utinam т IBI, 
ромге, quae est'тия indulgentia, animus non displiceat, quo hoc pietatis meae documentum ad т $\mathbf{x}$ defero, Deumque Optimum Maximum sollicitis precibus ambio, ut omnibus bonis, quibus felicitas humana, dignitasque Principalis censeri solet, IPSE cum AUGUSTA TUA Domo cumulatus, salutem, quam subditis TUIS animo in omnes imperii partes intento, cu- 
risque assiduis cupidissime paras, ad longissimam usque senectutem praestare possis! Ita sanctissime voveo

\section{SERENISSIME PRINCEPS AC DOMINE}

CELSITUDINI TUAE

DE VOT U S GOTTLIEB ERDMANN GIERIG. 